\title{
Brazilian Journal of Chemical

\section{SURFACE MORPHOLOGY OF SPRAY-DRIED NANOPARTICLE-COATED MICROPARTICLES DESIGNED AS AN ORAL DRUG DELIVERY SYSTEM}

\author{
R. C. R. Beck ${ }^{1}$, M. I. Z. Lionzo ${ }^{1}$, T. M. H. $\operatorname{Costa}^{2}$, E. V. Benvenutti ${ }^{2}$, M. I. Ré ${ }^{3}$, \\ M. R. Gallas ${ }^{4}$, A. R. Pohlmann ${ }^{1,2^{*}}$ and S. S. Guterres ${ }^{1}$ \\ ${ }^{1}$ Programa de Pós-Graduação em Ciências Farmacêuticas, Faculdade de Farmácia, \\ Universidade Federal do Rio Grande do Sul (UFRGS), Porto Alegre - RS, Brazil. \\ ${ }^{2}$ Instituto de Química, Universidade Federal do Rio Grande do Sul, Phone: +(55) (51) 3308-6274, \\ Fax: +(55) (51) 3308-7304, Cx P 15003, CEP: 91501-970, Porto Alegre - RS, Brazil. \\ E-mail: pohlmann@iq.ufrgs.br \\ ${ }^{3}$ Instituto de Pesquisas Tecnológicas do Estado de São Paulo S.A., \\ Divisão de Química, Cx P 0141, CEP: 01064-970, São Paulo - SP, Brazil. \\ ${ }^{4}$ Departamento de Física, Instituto de Física, Universidade Federal do Rio Grande do Sul, \\ CEP: 91501-970, Porto Alegre - RS, Brazil.
}

(Received: August 14, 2006 ; Accepted: January 18, 2008)

\begin{abstract}
This paper was devoted to studying the influence of coating material (nanocapsules or nanospheres), drug model (diclofenac, acid or salt) and method of preparation on the morphological characteristics of nanoparticle-coated microparticles. The cores of microparticles were obtained by spray drying or evaporation and the coating was applied by spray drying. SEM analyses showed nanostructures coating the surface of nanocapsule-coated microparticles and a rugged surface for nanosphere-coated microparticles. The decrease in their surface areas was controlled by the nanoparticulated system, which was not dependent on microparticle size. Optical microscopy and X-ray analyses indicated that acid diclofenac crystals were present in formulations prepared with the acid as well as in the nanocapsule-coated microparticles prepared with the salt. The control of coating is dependent on the use of nanocapsules or nanospheres and independent of either the characteristics of the drug or the method of preparing the core. Keywords: Coated microparticles; Nanoparticles; Nanocapsules; Spray drying; X-ray diffraction; SEM.
\end{abstract}

\section{INTRODUCTION}

Polymeric microparticles are widely studied in the pharmaceutical field for the purpose, among others, of obtaining better results in the oral administration of drugs by the production of multiple-unit drug delivery systems (Kawashima et al., 1993; Lin and Kao, 1991). These systems have several advantages, such as (Kawashima et al., 1993; Lin and Kao, 1991; Murilo et al., 2002) ready distribution over a large surface area, more constant drug plasma levels, higher accuracy in reproducibility dose by dose, no negative impact on bioavailability, lower risk of toxicity due to dose dumping, gastrointestinal tract protection from drug toxicity, labile drug protection from degradation in the gastrointestinal tract and antigen delivery to the Peyer's patches for oral immunization.

Microparticles can be prepared by several physical and chemical methods reported in the literature (Benita, 1996). One of these methods, the spray drying technique, has been successfully

*To whom correspondence should be addressed 
employed in the preparation of microparticulated delivery systems (Conte et al., 1994; Blanco et al., 2003; Huang et al., 2003; Oneda and Ré, 2003; Oliveira et al., 2005). This method offers advantages such as a rapid and one-step process, applicability to heat-sensitive materials and the possibility of scaleup (Wan et al., 1992). Despite the more complex and onerous production of the multiple-unit drug delivery systems they have several advantages over the single-unit systems.

In parallel, polymeric nanospheres and nanocapsules, which can be generically referred to as nanoparticles, are studied as drug carriers for the purpose of increasing drug efficacy, decreasing drug toxicity and/or developing prolonged drug delivery systems (Couvreur et al., 1995; Barrat, 2000; Schaffazick et al., 2003; Pohlmann et al., 2004). Nanospheres are composed of a matrix of polymer and nanocapsules are composed of an oily core and a polymer wall (Schaffazick et al., 2003). Methods for the preparation of nanoparticles can start from either monomers (interfacial polymerization method) or preformed polymers (nanoprecipitation and emulsification-diffusion methods) (Couvreur et al., 1995; Schaffazick et al., 2003). The polymers most often employed include poly(alkyl cyanoacrylate), poly(methyl methacrylate) or polyesters such as poly(e-caprolactone), poly(lactide) and poly(glycolide) and their copolymers. These polymeric nanoparticulated aqueous suspensions have some disadvantages during storage, such as microbiological contamination, polymer hydrolysis and/or physicochemical instability due to particle agglomeration and sedimentation.

The spray drying technique was proposed to obtain solid oral forms containing diclofenac-loaded nanoparticles, using colloidal silicon dioxide (Aerosil $200^{\circledR}$ ) as drying adjuvant (Müller et al., 2000; Guterres et al., 2000; Müller et al., 2001; Guterres et al., 2001; Pohlmann et al., 2002). The scanning electron microscopy analysis of spray dried powders showed spherical microparticles with nanoparticles on their surfaces (Müller et al., 2000; Pohlmann et al., 2002; Raffin et al., 2003). In parallel, silica nano and microparticles have been described as drug controlled release carriers prepared by sol-gel processes (Kortesuo et al., 2002; Smirnova et al., 2003), porous hollow silica nanoparticles (Chen et al., 2004) or organosilicate-polymer drug delivery systems (Cypes et al., 2003). Furthermore, silica particles have been studied for the adsolubilization of drugs and other substances on their surfaces, employing cationic or nonionic surfactants (Cherkaoui et al., 1998; Cherkaoui et al., 2000), and for development of powders for inhalation (Kawashima et al., 1998) and nanoparticles for in vitro gene transfer (Kneuer et al., 2000; Sameti et al., 2003).
In our previous work (Beck et al., 2004; Beck et al., 2006), we reported the use of nanoparticle suspensions (nanospheres or nanocapsules) as coating material for microparticles, whose cores were composed of drug and silicon dioxide. Diclofenac was used as the drug model. Its salt form was employed as the hydrophilic model and its free acid as the lipophilic model (Beck et al., 2004). The method was developed considering the physicochemical nature of the drug model. The in vitro drug release showed profiles for these systems modified depending on the characteristics of the drug (hydrophilic or lipophilic) and the coating material (nanospheres or nanocapsules). Also, we demonstrated the influence of coating material in protecting the gastrointestinal mucosa from the damaging effects of diclofenac (Beck et al., 2006). However, the influence of type of coating (nanospheres or nanocapsules) as well as its correlation with the characteristics of the drug on the morphological properties of these microparticles has not been established.

Considering that the influence of some factors, like surface area, particle size and surface morphology on the properties of microparticles should be known before designing drug delivery systems (Maia et al., 2004), this paper is devoted to determining the influence of coating material, characteristics of the drug and method of core preparation (spray drying or evaporation under reduced pressure) on the morphological characteristics of the coated microparticles. The morphological analyses were carried out using scanning electron and optical microscopies, X-ray diffraction and nitrogen adsorption-desorption isotherms to obtain the surface area and the pore size distribution.

\section{MATERIALS AND METHODS}

Diclofenac (sodium salt) was obtained from Sigma (St. Louis, USA); Eudragit S100 ${ }^{\circledR}$ (EUD) was supplied by Almapal (São Paulo, Brazil). Sorbitan monostearate (Span $60^{\mathbb{B}}$ ) and polysorbate 80 (Tween $80^{\circledR}$ ) were supplied by Delaware (Porto Alegre, Brazil). Colloidal silicon dioxide (Aerosil 200 ${ }^{\circledR}$ ) and the caprylic/capric triglyceride (Miglyol $810^{\mathbb{R}}$ ) were acquired from Degussa (São Paulo, Brazil) and Hulls (Puteau, France), respectively. All other chemicals and solvents were of pharmaceutical grade and were used as received.

\section{Preparation of Free Acid Diclofenac}

An aqueous solution (400 $\mathrm{mL})$ of sodium diclofenac $(3.0 \mathrm{~g}, 9.43 \mathrm{mmol})$ was acidified with 5 mol. $\mathrm{L}^{-1} \mathrm{HCl}(5 \mathrm{~mL})$. The precipitate (free acid form of 
diclofenac) was filtered and recrystallized from ethanol/water $1: 1 \quad(\mathrm{v} / \mathrm{v})$. Colorless crystals were obtained with a $90 \%$ of yield and characterized by infrared analysis (FT-IR 8300, Shimadzu, Tokio, Japan).

IR $\left(v, \mathrm{~cm}^{-1}\right): 3322(\mathrm{NH}), 2940(\mathrm{br}, \mathrm{OH}), 1694$ (CO), $1587(\mathrm{C}=\mathrm{C}), 1507$ and $1453(\mathrm{Ar}), 1160(\mathrm{C}-\mathrm{O})$.

\section{Preparation and Characterization of the Nanoparticle Suspensions}

Nanospheres (NS) were prepared by the nanoprecipitation method as described by Fessi and co-workers (Fessi et al., 1988). The lipophilic solution consisting of Span $60^{\circledR}(0.1532 \mathrm{~g})$, Eudragit $\mathrm{S} 100^{\circledR}(1.0 \mathrm{~g})$ and acetone $(267.0 \mathrm{~mL})$ was added under moderate magnetic stirring to an aqueous solution $(533.0 \mathrm{~mL})$ containing Tween $80^{\circledR}(0.1532$ g). The mixture was stirred for $10 \mathrm{~min}$ at room temperature. Thus, the acetone was eliminated and the aqueous phase concentrated by evaporation under reduced pressure. The final volume was adjusted to $100 \mathrm{~mL}$, corresponding to a polymer concentration of $10 \mathrm{mg} \cdot \mathrm{mL}^{-1}$. Nanocapsules (NC) were prepared in a similar way, but adding Miglyol $810^{\mathbb{B}}(3.30 \mathrm{~mL})$ to the acetone solution. The formulations were prepared in triplicate.

Nanoparticle suspensions (NC and NS) were characterized by measurements of $\mathrm{pH}$ (Micronal, B474, São Paulo, Brazil) and by photon correlation spectroscopy (PCS) after dilution of samples (500 times) with water (Milli- $Q^{\circledR}$ ). The scattered light was observed at an angle of $90^{\circ}$ (Brookheaven Instruments, goniometer BI-200M/2.0 version, Holtsville, USA; BI9863 detection system; Laser He-Ne source 35
mW, 127 model, $\lambda=632.8 \mathrm{~nm}$, Spectra Physics, Mountain View, USA). Measurements were carried out in triplicate.

\section{Preparation of the Microparticles}

The microparticles were prepared in triplicate as previously reported (Beck et al., 2004) considering the solubility of the drug. Fig. 1 shows the illustrative methods used to prepare formulations containing hydrophilic (sodium diclofenac) or lipophilic (free acid diclofenac) models. These methods are described below.

\section{- Hydrophilic Drug-Loaded Microparticles}

The sodium diclofenac $(0.270 \mathrm{~g}, 0.7 \mathrm{mmol})$ was dissolved in water $(50 \mathrm{~mL})$ and added to Aerosil $200^{\circledR}(1.5 \mathrm{~g})$ in order to obtain the core of the microparticles (uncoated core-DicONa) (Fig. 1). This mixture was fed into a Büchi $190^{\circledR}$ mini spray dryer (Flawil, Switzerland) with a two-component nozzle and co-current flow to give a powder (the core) with a final concentration of sodium diclofenac of $0.48 \mathrm{mmol} . \mathrm{g}^{-1}$. The inlet temperature of the drying chamber was maintained at around $170 \pm 4{ }^{\circ} \mathrm{C}$ and the feed rate was $3 \mathrm{~mL} \cdot \mathrm{min}^{-1}$. In the coating step, 1.5 $\mathrm{g}$ of the core material, which corresponds to $0.230 \mathrm{~g}$ $(0.7 \mathrm{mmol})$ of sodium diclofenac in $1.270 \mathrm{~g}$ of silicon dioxide, was rapidly dispersed into the $\mathrm{NC}$ or NS aqueous suspensions $(50 \mathrm{~mL})$ under magnetic stirring at room temperature. This mixture was also spray dried as described above. The powders ware referred to as called NC-coated-MP-DicONa and NS-coated-MP-DicONa, respectively.

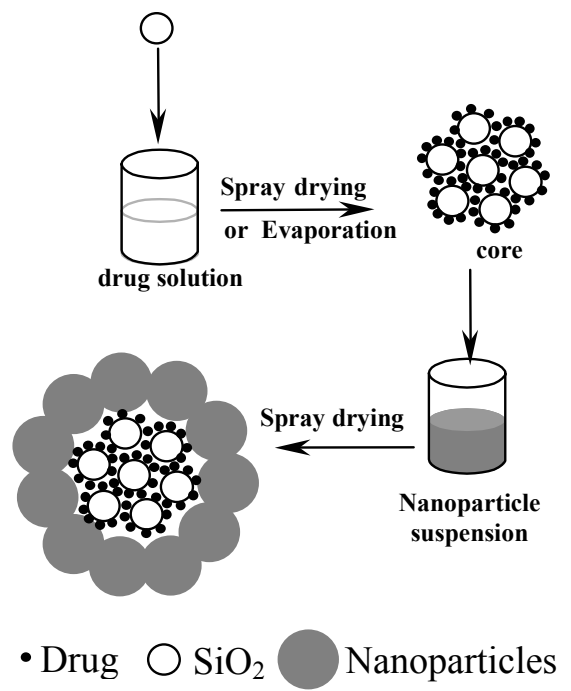

Figure 1: Schematic preparation of DicOH- or DicONa-loaded nanoparticle-coated microparticles. The final particles can have multicore structures. 


\section{- Lipophilic Drug-Loaded Microparticles}

The free acid diclofenac $(0.250 \mathrm{~g}, 0.7 \mathrm{mmol})$ was dissolved in acetone $(50 \mathrm{~mL})$ and added to Aerosil $200^{\circledR}(1.5 \mathrm{~g})$ in order to obtain the core of the microparticles (uncoated core-DicOH) (Fig. 1). The acetone was eliminated under reduced pressure to obtain a solid product with a final diclofenac concentration of $0.48 \mathrm{mmol} . \mathrm{g}^{-1}$. This powder (the core) was maintained in a desiccator at room temperature during $48 \mathrm{~h}$. In the coating step, $1.5 \mathrm{~g}$ of core material, which corresponds to $0.214 \mathrm{~g}(0.7$ $\mathrm{mmol}$ ) of diclofenac in $1.270 \mathrm{~g}$ of silicon dioxide, was carefully milled in a mortar for $10 \mathrm{~min}$ and dispersed in the NC or NS aqueous suspensions (50 $\mathrm{mL}$ ) under magnetic stirring at room temperature. The mixture was fed into a Büchi $190^{\circledR}$ mini spray dryer (Flawil, Switzerland). The powders are referred to as NC-coated-MP-DicOH and NS-coatedMP-DicOH, respectively

\section{Determination of Yield and Encapsulation Efficiency}

The powder yields were calculated by the sum of the weights of all components of the formulation, minus the water content in the original suspension. Each powder was dispersed in acetonitrile (DicOHcontaining formulations) or buffer $\mathrm{pH} 7.4$ (DicONacontaining formulations) for $60 \mathrm{~min}$ at room temperature. The dispersions were filtered through a hydrophilic membrane (GVWP, $0.45 \mu \mathrm{m}$, Millipore) and analyzed by HPLC. The chromatographic system consisted of a Nova Pak ${ }^{\circledR}$ RP 18 -Waters column and a Perkin Elmer instrument (200 Series, Shelton, USA). The mobile phase was prepared using 1:1 (v/v) acetonitrile and phosphate buffer $\mathrm{pH}$ 5.0. The volume injected was $20 \mu \mathrm{L}$, the flow was 1 $\mathrm{mL} \cdot \mathrm{min}^{-1}$ and diclofenac was detected at $280 \mathrm{~nm}$. The encapsulation efficiency of each formulation was calculated from the correlation of the theoretical and the experimental diclofenac concentrations and expressed as percentages.

\section{Morphological Analyses}

\section{- Nitrogen Isotherms}

The solids had been previously degassed under vacuum at $40{ }^{\circ} \mathrm{C}$ for 2 hours. The nitrogen adsorption-desorption isotherms were determined at the liquid nitrogen boiling point in a homemade volumetric apparatus, using nitrogen as probe. The apparatus was frequently checked with an alumina
Aldrich standard reference (150 mesh, $5.8 \mathrm{~nm}$ and $\left.155 \mathrm{~m}^{2} \cdot \mathrm{g}^{-1}\right)$. The specific surface areas of microparticles were determined by the BET multipoint technique (Brunauer et al., 1938) and the pore size distribution was obtained using the $\mathrm{BJH}$ method (Barret et al., 1951).

\section{- Scanning Electron Microscopy}

The uncoated cores and the nanoparticle-coated microparticles were examined by scanning electron microscopy (SEM) (Jeol Scanning Microscope, JSM-5800, Tokyo, Japan) at $20 \mathrm{kV}$, employing different magnifications (between 1,000x and 95,000x). Samples were analyzed after they had been gold sputtered (Jeol Jee 4B SVG-IN, Tokyo, Japan).

\section{- Optical Microscopy}

The uncoated core and the microparticles were examined at a magnification of $120 \mathrm{x}$, after redispersion in water, phosphate buffer $\mathrm{pH} 7.4$ or mineral oil. The apparatus consisted of a light microscope (Olympus ${ }^{\circledR}$, model BX-41, Japan) coupled to a photographic camera (Olympus ${ }^{\circledR}$, model PM-20, Japan).

\section{- Particle Size and Size Distribution}

Particle size and size distribution were determined by laser diffractometry using a Beckman Coulter - tornado (Beckman Instruments, USA) by drying dispersion laser diffractometry using a Malvern laser sizer. Average particle size was expressed as volume mean diameter $\left(\mathrm{d}_{4,3}\right)$ in $\mu \mathrm{m}$. Polydispersity was given by a span index, which was calculated by $\left(\mathrm{d}_{0.9}-\mathrm{d}_{0.1}\right) / \mathrm{d} 0.5$ where $\mathrm{d}_{0.9}, \mathrm{~d}_{0.5}$ and $\mathrm{d}_{0.1}$ are the particle diameters determined respectively at the $90^{\text {th }}, 50^{\text {th }}$ and $10^{\text {th }}$ percentile of undersized particles.

\section{- X-Ray Analyses}

X-ray analyses were performed on the polymer, on the drug (diclofenac and sodium diclofenac) and on the microparticles. Diffraction powder patterns were obtained with a Siemens D500 diffractometer using $\mathrm{Cu} \mathrm{K} \alpha$ radiation at $35 \mathrm{kV}$.

\section{RESULTS AND DISCUSSION}

In this paper, polymeric nanoparticles were used as nanostructured coating for drug-loaded 
microparticles. The nanoparticle aqueous suspensions were prepared by nanoprecipitation of Eudragit $\mathrm{S}_{100}{ }^{\circledR}$. After preparation, the suspensions had $\mathrm{pH}$ values of $3.71 \pm 0.03$ and $3.60 \pm 0.01$ and particle sizes of $119 \pm 1 \mathrm{~nm}$ and $67 \pm 9 \mathrm{~nm}$ as determined by dynamic light scattering (PCS) for NC and NS suspensions, respectively.

The NC- and NS-coated drug-loaded microparticles were prepared using sodium diclofenac as the hydrophilic drug model and free acid diclofenac as the lipophilic model. The acid form of diclofenac was prepared by the classical procedure of reaction the commercial sodium diclofenac with 5 mol.L $\mathrm{L}^{-1}$ $\mathrm{HCl}$. A very good yield was obtained $(90 \%)$ and its IR spectrum showed bands at 3322, 2940, 1694, 1587 and $1160 \mathrm{~cm}^{-1}$ corresponding to stretching of $\mathrm{NH}, \mathrm{OH}$ and $\mathrm{C}=\mathrm{O}, \mathrm{C}=\mathrm{C}$ and $\mathrm{C}-\mathrm{O}$.

The NC- and NS-coated drug-loaded microparticle yields ranged from 40 to $80 \%$ and the encapsulation efficiencies were between 79 and $98 \%$. All samples phad a macroscopic aspect of powder. The SEM analyses of formulations whose cores were prepared by evaporation ahowed agglomerates with a wide range of diameters (Fig.2b and 2c). On the other hand, those whose cores were obtained by spray drying, showed agglomerates of narrower sized microparticles (Fig. 2e and 2f). Regarding the cores, the uncoated core-DicONa had sphere shaped agglomerates, while the uncoated core-DicOH shad irregular agglomerates. These differences are consequences of the method of core preparation, spray drying and solvent evaporation, respectively.

Concerning the analyses of microparticle surfaces (Fig. 3), NC-coated formulations had nanostructures with diameters similar to those observed by PCS for the original suspension, while NS-coated formulations (NS-coated-MP-DicOH and NScoated-MP-DicONa) had rugged surfaces as previously observed by SEM (Beck et al., 2004). These different surface morphologies could result in different surface areas. In order to confirm this hypothesis, the surface areas and the pore volumes were determined by $\mathrm{N}_{2}$ adsorption-desorption isotherms using the BET and BJH methods (Table 1). The commercial silicon dioxide (Aerosil 200 ${ }^{\circledR}$ ) was also analyzed as control and it had a surface area of 214 $\mathrm{m}^{2} \cdot \mathrm{g}^{-1}$ and a pore volume of $0.30 \mathrm{~cm}^{3} \cdot \mathrm{g}^{-1}$. Comparing the uncoated drug-loaded cores with the Aerosil $200^{\circledR}$, the surface areas was smaller with no difference in pore volume (uncoated core-DicONa: $151 \mathrm{~m}^{2} \cdot \mathrm{g}^{-1}$ and 0.26 $\mathrm{cm}^{3} \cdot \mathrm{g}^{-1}$; uncoated core-DicOH: $163 \mathrm{~m}^{2} \cdot \mathrm{g}^{-1}$ and 0.25 $\left.\mathrm{cm}^{3} \cdot \mathrm{g}^{-1}\right)$. Furthermore, the surface areas showed an additional decrease after coating the cores using the nanoparticle suspension. These values for the NC- coated microparticles decreased more than those for the NS-coated microparticles, independently of the drug model (lipophilic or hydrophilic): NC-coated-MPDicONa: $50 \mathrm{~m}^{2} \cdot \mathrm{g}^{-1}$; NS-coated-MP-DicONa: $126 \mathrm{~m}^{2} \cdot \mathrm{g}^{-}$ ; NC-coated-MP-DicOH: $60 \mathrm{~m}^{2} \cdot \mathrm{g}^{-1}$ and NS-coatedMP-DicOH: $132 \mathrm{~m}^{2} \cdot \mathrm{g}^{-1}$.

The pore size distributions of Aerosil 200 ${ }^{\circledR}$, uncoated cores and respective NC- and NS-coated microparticles were determined using the $\mathrm{BJH}$ method (Barret et al., 1951). In the mesoporous region (pore diameter between 2 and $50 \mathrm{~nm}$ ) all samples had similar distribution profiles near zero. The macropores of Aerosil $200^{\circledR}$ from the agglomeration of its particles, and the presence of nanostructures and/or drug (organic materials) in the agglomerates product the decreases in surface areas (Table 1).

The decrease in surface area could be due to the different size distributions. In order to evaluate this hypothesis, the powders were analyzed by laser diffractometry. The mean microparticle sizes and size ranges of the uncoated cores and the NC- and NS-coated microparticles are presented in Table 2. The NC- and NS-coated DicOH-loaded microparticles were of particle sizes slightly larger than the respective uncoated core (NC-coated-MPDicOH: $10.11 \mu \mathrm{m}$; NS-coated-MP-DicOH: 12.33 $\mu \mathrm{m}$ and uncoated-core DicOH: $7.27 \mu \mathrm{m}$ ). On the other hand, the particle sizes of NC- and NS-coated DicONa-loaded microparticles were slightly smaller than the respective uncoated core (NC-coated-MPDicONa: $6.17 \mu \mathrm{m}$; NS-coated-MP-DicONa-2: 6.19 $\mu \mathrm{m}$ and uncoated core-DicONa: $11.07 \mu \mathrm{m})$. These results showed that the decrease in the surface area was not related to the increase in microparticle size, but to the presence of organic material (polymeric nanostructures) on the surface of the microparticles. Furthermore, the results suggest that a desagglomeration/agglomeration process took place when the cores were added to the respective $\mathrm{NC}$ and NS suspensions. This rearrangement would be more extensive for DicONa-loaded core than for DicOHloaded core due to the solubility of the salt and the acid diclofenac in the aqueous medium. The DicOHloaded core was more hydrophobic than the DicONa-loaded core, which had a hydrophilic characteristics. Analyzing the span values (Table 2) we could demonstrate the lower polydispersity of DicONa-loaded microparticles (NC-coated-MPDicONa:2.25; NS-coated-MP-DicOH: 2.22), as observed by electron microscopy (Figure 2). In addition, the low polydispersity values of these formulations are in agreement with those in other works in the literature (Maia et al., 2004; Oneda and Ré, 2003). 
Table 1: Microparticle size according to the type of microparticle sample (drug-loaded uncoated core or nanoparticle-coated microparticles).

\begin{tabular}{|c|c|c|c|}
\hline Sample & BET Surface area $\left(\mathrm{m}^{2} \cdot \mathrm{g}^{-1}\right)$ & Correlation coefficient & BJH Pore volume $\left(\mathrm{cm}^{3} \cdot \mathrm{g}^{-1}\right)$ \\
\hline Uncoated core - DicOH & $163 \pm 08$ & 0.9989 & $0.250 \pm 0.010$ \\
\hline Uncoated core - DicONa & $151 \pm 08$ & 0.9992 & $0.260 \pm 0.010$ \\
\hline NC-coated-MP-DicOH & $60 \pm 03$ & 0.9999 & $0.070 \pm 0.005$ \\
\hline NS-coated-MP-DicOH & $132 \pm 07$ & 0.9988 & $0.220 \pm 0.010$ \\
\hline NC-coated-MP-DicONa & $50 \pm 02$ & 0.9932 & $0.070 \pm 0.005$ \\
\hline NS-coated-MP-DicONa & $126 \pm 06$ & 0.9998 & $0.220 \pm 0.010$ \\
\hline
\end{tabular}

Table 2: Microparticle size according to the type of microparticle sample (drug-loaded uncoated core or nanoparticle-coated microparticles).

\begin{tabular}{|l|c|c|c|c|c|}
\hline \multirow{2}{*}{ Sample } & Mean volume diameter & \multicolumn{4}{|c|}{ Particle size distributions } \\
\cline { 2 - 6 } & $\mathbf{d}_{\mathbf{4 . 3}}(\boldsymbol{\mu} \mathbf{m})$ & $\mathbf{d}_{\mathbf{0 . 9}}(\boldsymbol{\mu} \mathbf{m})$ & $\mathbf{d}_{\mathbf{0 . 1}}(\boldsymbol{\mu} \mathbf{m})$ & \multicolumn{1}{|c|}{ Span } & $<\mathbf{1 0} \boldsymbol{\mu m} \mathbf{( \% )}$ \\
\hline Uncoated core - DicOH & 7.27 & 12.74 & 2.75 & 1.59 & 71.7 \\
Uncoated core - DicONa & 11.07 & 27.99 & 2.50 & 3.73 & 63.6 \\
NC-coated-MP-DicOH & 10.11 & 25.59 & 1.14 & 4.10 & 64.6 \\
NS-coated-MP-DicOH & 12.33 & 30.01 & 1.52 & 4.15 & 58.4 \\
NC-coated-MP-DicONa & 6.17 & 12.00 & 1.24 & 2.25 & 81.5 \\
NS-coated-MP-DicONa & 6.19 & 12.69 & 1.81 & 2.22 & 82.6 \\
\hline
\end{tabular}

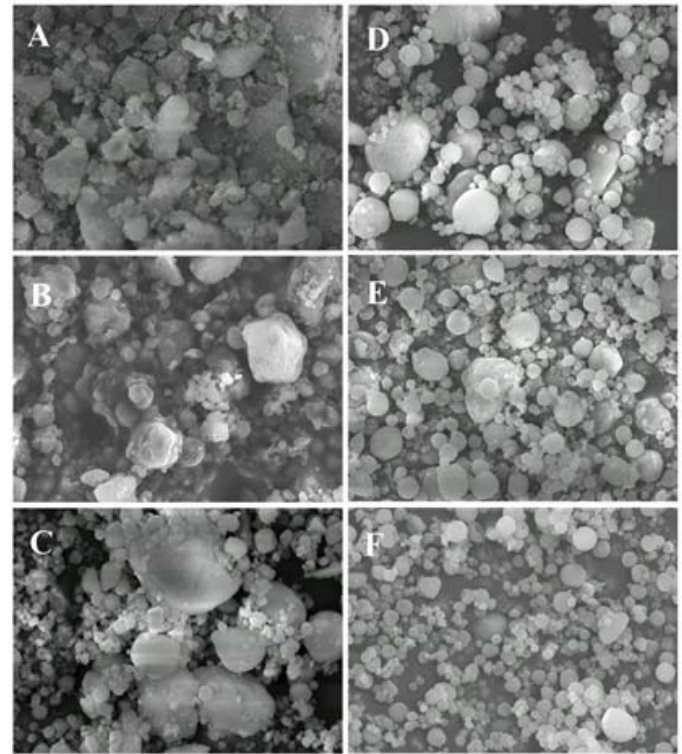

Figure 2: SEM (photo width $=132 \mu \mathrm{m}$ ) of lipophilic drug-loaded samples: (A) uncoated core-DicOH, (B) NCcoated-MP-DicOH, (C) NS-coated-MP-DicOH, and hydrophilic drug-loaded samples: (D) uncoated coreDicONa, (E) NC-coated-MP-DicONa, (F) NS-coated-MP-DicONa. 


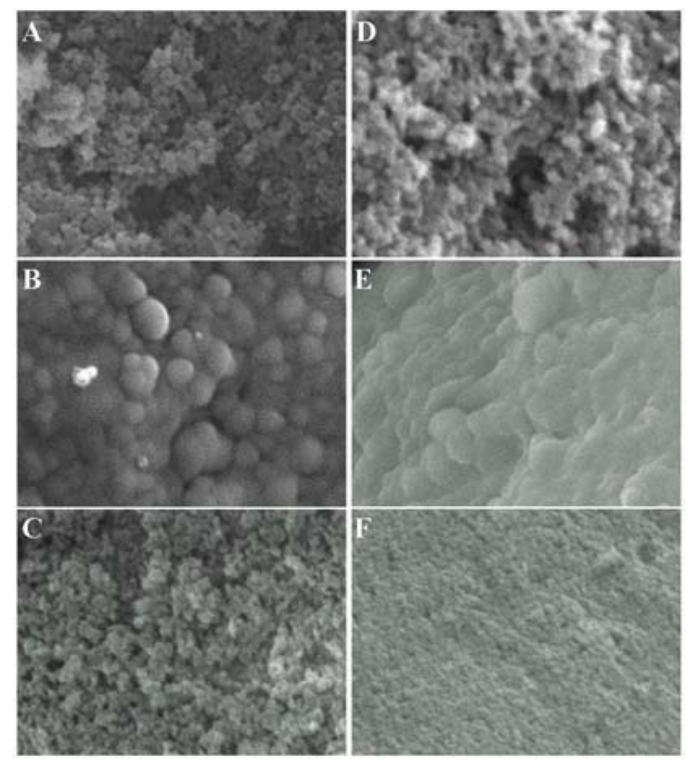

Figure 3: SEM (photo width $=2.93 \mu \mathrm{m}$ ) of lipophilic drug-loaded samples: (A) uncoated core-DicOH, (B) NCcoated-MP-DicOH, (C) NS-coated-MP-DicOH, and hydrophilic drug-loaded samples: (D) uncoated coreDicONa, (E) NC-coated-MP-DicONa, (F) NS-coated-MP-DicONa.

The optical microscopic analyses of the uncoated cores and the respective microparticles dispersed in water showed spherical agglomerates for the DicONa-loaded microparticles and irregular agglomerates for the DicOH-loaded microparticles. Crystalline structures were observed only in the uncoated core-DicOH and NS-coated-MP-DicOH. After dispersion of these powders in phosphate buffer $\mathrm{pH} \mathrm{7.4,} \mathrm{the} \mathrm{crystalline} \mathrm{structures} \mathrm{could} \mathrm{not} \mathrm{be}$ seen (data not shown).

Aiming to confirm that these crystals could correspond to the drug and to investigate the physical state of the drug in the formulations, X-ray analyses were performed. The X-ray diffraction patterns for the free acid diclofenac (A), sodium diclofenac (B) and the polymer Eudragit $\mathrm{S} 100^{\circledR}$ (C) are shown in Fig. 4. The diffractograms from $\mathrm{D}$ to $\mathrm{I}$ are the experimental results for the different microparticle samples. Diffraction peaks seen in the DicOH-loaded microparticles (D, F and G) correspond to the pattern of the free acid diclofenac. These peaks are superimposed on the amorphous silica pattern that has a very broad diffraction line at $2 \theta \approx 22^{\circ}$. On the other hand, the uncoated core-DicONa diffractogram does not show any peak. The absence of crystallinity in this uncoated core indicates that the DicONa was either amorphous or molecularly dispersed within the microparticles. The NC-coated-MP-DicONa (H) diffractogram has a diffraction peak of free acid diclofenac crystals, while the NS-coated-MP-DicONa (I) diffractogram has broad diffraction lines corresponding to the polymer and silicon dioxide. A very broad diffraction line of the polymer $(C)\left(2 \theta \approx 13^{\circ}\right)$ can also be observed for all NC or NS-coated formulations (F-I).

The presence of free acid diclofenac crystals [diclofenac $\mathrm{pK}_{\mathrm{a}} 3.8$ at $25{ }^{\circ} \mathrm{C}$ (Chiarini et al., 1984)] in the NC-coated-MP-DicONa $(\mathrm{H})$ and its absence in the uncoated core-DicONa indicate that its dispersion in the nanocapsule suspension resulted in a partial protonation of the drug during preparation due to the acid $\mathrm{pH}$ of the suspension $(\mathrm{pH} 3.71 \pm$ 0.01 ) and the more hydrophobic characteristic of the NC than of the NS particles. The diffraction peaks of $\mathrm{DicOH}$ observed for uncoated core-DicOH and NScoated-MP-DicOH confirm that the crystals observed by optical microscopy correspond to the drug in its acid form. The presence of microcrystals in the DicOH-loaded formulations can explain the slow release profile for diclofenac from NS-coatedMP-DicOH at pH 7.4, as previously reported (Beck et al., 2004).These results suggest that the hypothesis raised above, which assumed a desagglomeration/ agglomeration process after adding the cores to the nanoparticle suspensions, is valid. Thus, the structure of coated microparticles probably corresponds to multicore particles. 


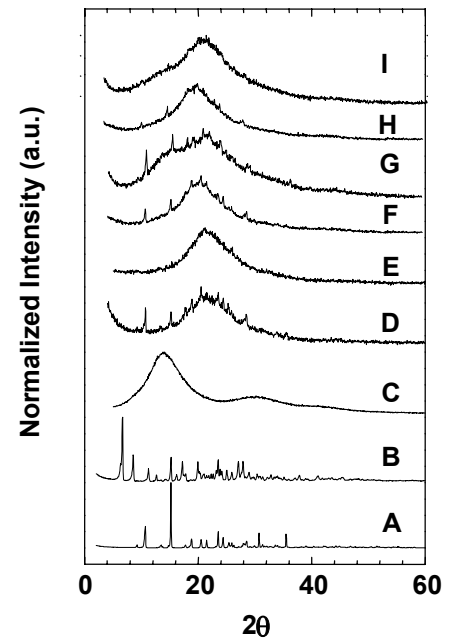

Figure 4: X-ray diffraction pattern of (A) DicOH; (B) DicONa; (C) Eudragit S100 ${ }^{\circledR}$; (D) Uncoated core-DicOH; (E) Uncoated core-DicONa; (F) MP-NC-DicOH;

(G) MP-NS-DicOH; (H) MP-NC-DicONa and (I) MP-NS-DicONa.

\section{CONCLUSIONS}

The SEM analyses of powders showed that the shape of the microparticles depend on the proces involved in their preparation (evaporation under reduced pressure and/or spray drying). These analyses also showed a morphological difference on the surface of the microparticles. NC-coated microparticles had nanostructures coating their surfaces, whereas NS-coated microparticles had rugged surfaces. These differences in surface morphology were accompanied by differences in surface area between the products and between both products and the commercial silicon dioxide. Microparticle size did not influence the surface area of the powders. DicONa-loaded microparticles had slightly smaller mean sizes than their respective cores and lower polydispersity than the other formulations. In addition, the optical microscopy and the X-ray analyses showed the presence of crystals in all DicOH-loaded formulations. Free acid diclofenac crystals were also detected by X-ray diffraction in sodium diclofenac-loaded formulation prepared with nanocapsule suspensions (NC-coated-MP-DicONa).

The overall morphological studies conducted in this work showed that the NC- and NS can produce different and specific coatings of microparticles. The control of coating is achieved by using different coating materials, $\mathrm{NC}$ or NS, and is not dependent on either the physicochemical characteristics of the drug (hydrophilic or lipophilic models) or the method of preparing the core (spray drying or evaporation under reduced pressure).

\section{ACKNOWLEDGEMENTS}

RCRB thanks Capes for his fellowship. The authors are grateful for the financial support of FAPERGS, Rede Nanobiotec/CNPq/MCT, and the grant received from $\mathrm{CNPq} /$ Brasília/Brazil. SEM analyses were carried out in the Centro de Microscopia da UFRGS.

\section{REFERENCES}

Barratt, G. M., Therapeutic applications of colloidal drug carriers. Pharmaceutical Science \& Technology Today, 3, 163-171 (2000).

Barret, E. P., Joyner, L. G. and Halenda, P. P., The determination of pore volume and area distributions in porous substances. I. Computations from nitrogen isotherms. Journal of the American Chemical Society, 73, 373-380 (1951).

Beck, R. C. R. B., Haas, S. E., Guterres, S. S., Ré, M. I., Benvenutti, E. V. and Pohlmann, A. R., Nanoparticle-coated organic-inorganic microparticles: Experimental design and gastrointestinal tolerance evaluation, Quimica Nova, 29, 990-996 (2006).

Beck, R. C. R., Pohlmann, A. R. and Guterres, S. S., Nanoparticle coated microparticles: Preparation and characterization, Journal of Microencapsulation, 21, 499-512 (2004).

Benita, S., Microencapsulation: Methods and Industrial Applications, Marcel Dekker, New 
York, USA (1996).

Blanco, M. D., Bernardo, M. V., Sastre, R. L., Olmo, R., Muñiz, E. and Teijón, J. M., Preparation of bupivacaine-loaded poly( $\varepsilon$-caprolactone) microspheres by spray-drying: Drug release studies and biocompatibility, European Journal of Pharmaceutics and Biopharmaceutics, 55, 229236 (2003).

Brunauer, S., Emmet, P. H. and Teller, E., Adsorption of gases in multimolecular layers, Journal of the Chemical Society, 60, 309-319 (1938).

Chen, J.-G., Ding, H.-M., Wang, J. X. and Shao, L., Preparation and characterization of porous hollow silica nanoparticles for drug delivery application, Biomaterials, 25, 723-727 (2004).

Cherkaoui, I., Monticone, V., Vaution, C. and Treiner, C., Coadsorption of the sodium salts of two steroid molecules at a silica/interface as induced by the adsorption of a cationic surfactant, International Journal of Pharmaceutics, 201, 7177 (2000).

Cherkaoui, I., Monticone, V., Vaution, C. and Treiner, C., Surface modification of silica particles by a cationic surfactant: Adsolubilization of steroids from aqueous solutions, International Journal of Pharmaceutics, 176, 111-120 (1998).

Chiarini, A., Tartarini, A. and Fini, A., pH-solubility relationship and partition coefficients for some anti-inflammatory arylaliphatic acids, Archiv der Pharmazie, 317, 268-273 (1984).

Conte, U., Conti, B., Giunchedi, P. and Maggi, L., Spray dried polylactide microsphere preparation: Influence of the technological parameters, Drug Development and Industrial Pharmacy, 20, 235258 (1994).

Couvreur, P., Dubernet, C. and Puisieux, F., Controlled drug delivery with nanoparticles: Current possibilities and future trends, European Journal of Pharmaceutics and Biopharmaceutics, 41, 2-13 (1995).

Cypes, S. H., Saltzman, W. M. and Giannelis, E. P., Organosilicate-polymer drug delivery systems: Controlled release and enhanced mechanical properties, Journal of Controlled Release, 90, 163-169 (2003).

Fessi, H., Puisieux, F. and Devissaguet, J.-Ph., European Patent 0274961, A1 (1988).

Guterres, S. S., Müller, C. R., Pohlmann, A. R. and Dalla-Costa, T., Gastro-intestinal tolerance following oral administration of spray-dried diclofenac-loaded nanocapsules and nanospheres. STP Pharma Sciences, 11, 229-233 (2001).
Guterres, S. S., Pohlmann, A. R., Dalla-Costa, T., Bassani, V. L. and Muller, C. R., Procédé de séchage de suspensions colloïdales de nanocapsules et de nanospheres polymères par aspersion, French Patent 2,801,227 (2000).

Huang, Y. C., Chiang, C. H. and Yeh, M. K., Optimizing formulation factors in preparing chitosan microparticles by spray-drying methods, Journal of Microencapsulation, 20, 247-260 (2003).

Kawashima, Y., Iwamoto, T., Niwa, T., Takeuchi, H. and Hino, T., Uniform and improved bioavailability of newly developed rapid and sustained release suspensions of ibuprofen microspheres, International Journal of Pharmaceutics, 89, 9-17 (1993).

Kawashima, Y., Serigano, T., Hino, T., Yamamoto, H. and Takeuchi, H., Design of inhalation dry powder of pranlukast hydrate to improve dispersibility by the surface modification with light anhydrous silicic acid (Aerosil 200), International Journal of Pharmaceutics, 173, 243251 (1998).

Kneuer, C., Sameti, M., Bakowsky, U., Schiestel, T., Schirra, H., Schmidt, H. and Lehr, C.-M., A nonviral DNA delivery system based on the surface modified silica-nanoparticles can efficiently transfect cells in vitro, Bioconjugate Chemistry, 11, 926-932 (2000).

Kortesuo, P., Ahola, M., Kangas, M., Jokinen, M., Leino, T., Vuorilehto, L., Laakso, S., Kiesvaara, J., Yli-Urpo, A. and Marvola, M., Effect of synthesis parameteres of the sol-gel-processed spray-dried silica gel microparticles on the release rate of dexmedetomidine, Biomaterials, 23, 2795-2801 (2002).

Lin, S. and Kao, Y., Tablet formulation study of spray-dried sodium diclofenac enteric-coated microcapsules, Pharmaceutical Research, 8, 919924 (1991).

Maia, J. L., Santana, M. H. A. and Ré, M. I., The effect of some processing conditions on the characteristics of biodegradable microspheres obtained by an emulsion solvent evaporation process, Brazilian Journal of Chemical Enginnering, 21, 1-12 (2004).

Müller, C. R., Bassani, V. L., Pohlmann, A. R., Michalowski, C. B., Petrovick, P. R. and Guterres S. S., Preparation and characterization of spraydried polymeric nanocapsules, Drug Development and Industrial Pharmacy, 26, 343347 (2000).

Muller, C. R., Schaffazick, S. R., Pohlmann, A. R., 
Freitas, L. L., da Silveira, N. P., Dalla-Costa, T. and Guterres, S. S., Spray-dried diclofenacloaded poly( $\varepsilon$-caprolactone) nanocapsules and nanospheres: Preparation and physicochemical characterization, Pharmazie, 56, 864-867 (2001).

Murillo, M., Gamazo, C., Goñi, M. M., Irache, J. M. and Blanco-Príeto, M. J., Development of microparticles prepared by spray-drying as a vaccine delivery system against brucellosis, International Journal of Pharmaceutics, 242, 341344 (2002).

Oliveira, B. F., Santana M. H. A. and Ré, M. I., Spray-dried chitosan microspheres cross-linked with d, l-glyceraldehyde as a potential drug delivery system: Preparation and characterization, Brazilian Journal of Chemical Engineering, 22, 353-360 (2005).

Oneda, F. and Ré, M. I., The effect of formulation variables on the dissolution and physical properties of spray-dried microspheres containing organic salts, Powder Technology, 130, 377-384 (2003).

Pohlmann, A. R., Soares, L. U., Cruz, L., da Silveira, N. P. and Guterres, S. S., Alkaline hydrolysis as a tool to determine the association form of indomethacin in nanocapsules prepared with poly( $\varepsilon$-caprolactone), Current Drug Delivery, 1, 103-110 (2004).

Pohlmann, A. R., Weiss, V., Mertins, O., da Silveira,
N. P. and Guterres, S. S., Spray-dried indomethacin-loaded polyester nanocapsules and nanospheres: Development, stability evaluation and nanostructure models, European Journal of Pharmaceutical Sciences, 16, 305-312 (2002).

Raffin, R. P., Obach, E. S., Mezzalira, G., Pohlmann, A. R. and Guterres, S. S., Nanocápsulas poliméricas secas contendo indometacina: estudo de formulação e de tolerância gastrintestinal em ratos, Acta Farm Bonaerense, 22, 163-172 (2003).

Sameti, M., Bohr, G., Ravi Kumar, M. N. V., Kneuer, C., Bakowsky, U., Nacken, M., Schmidt, H. and Lehr, C.-M., Stabilisation by freeze-drying of cationially modified silica nanoparticles for gene delivery, International Journal of Pharmaceutics, 266, 51-60 (2003).

Schaffazick, S. R., Guterres, S. S., Freitas, L. L. and Pohlmann, A. R., Caracterização e estabilidade físico-química de sistemas poliméricos nanoparticulados para administração de fármacos, Quimica Nova, 26, 726-737 (2003).

Smirnova, I., Mamic, J. and Arlt, W., Adsorption of drugs on silica aerogels, Langmuir, 19, 85218525 (2003).

Wan, L. S. C., Heng, W. S. C. and Chia, G. H., Spray drying as a process for microencapsulation and the effect of different coating polymers, Drug Development and Industrial Pharmacy, 18, 9971011 (1992). 